\title{
Damping Characteristics of TiNi Shape Memory Alloys
}

\author{
H.C. LIN, S.K. WU, and M.T. YEH \\ The damping characteristics of TiNi SMAs have been systematically studied by using techniques \\ of resonant-bar and low-frequency inverted torsion pendulum. Experimental results show that \\ both the martensite phase (M) and $R$ phase (R) have high damping due to the movement of \\ twin boundaries. Because the B2 parent phase (B2) has smaller damping, it is suggested that \\ this may come from the dynamic ordering process of lattice defects. In the transformation re- \\ gions of B2 $\leftrightarrow \mathrm{M}, \mathrm{B} 2 \leftrightarrow \mathrm{R}$, and $\mathrm{R} \leftrightarrow \mathrm{M}$, there are maxima of the damping capacity which \\ are attributed to two contributions. One arises from the plastic strain and twin-interface move- \\ ment during the thermal transformation, which obeys a linear variation of peak heights $Q_{\max }^{-1} v s$ \\ $\dot{T}$ at $\dot{T} \geq 1{ }^{\circ} \mathrm{C} / \mathrm{min}$. The other originates from the stress-induced transformation formed by the \\ applied external stress which dominates at $T<1{ }^{\circ} \mathrm{C} / \mathrm{min}$. The elastic modulus $E$ of martensite \\ and the $\mathrm{R}$ phase is lower than that of the $\mathrm{B} 2$ phase, and a modulus minimum appears in the \\ transformation region.
}

\section{INTRODUCTION}

TiNi alloys are known as the most important shape memory alloys (SMAs) because of their many applications based on the shape memory effect (SME) and pseudoelasticity (PE). This comes from the fact that TiNi alloys have superior properties in ductility, strength, fatigue, corrosion resistance, recoverable strain, etc. It is also well known that TiNi alloys can exhibit high mechanical damping. ${ }^{[1-4]}$ However, our understanding in this area is incomplete. No systematic investigation has been reported on the damping characteristics of TiNi SMAs.

Damping mechanisms, in general, involve the stressinduced movement of defects. For high-damping metals, the major mechanisms are the stress-induced movement of dislocations or planar defects. ${ }^{|5|}$ Most of these mechanisms can be phenomenologically split into three classes: dynamic hysteresis, static hysteresis, and transformation mechanisms. Dynamic hysteresis is produced by the stressaided ordering of defects overcoming local barriers by thermal activation and yields damping that is frequency dependent and amplitude independent. Static hysteresis appears due to the stress-induced "unpinning" or "breakaway" process of the defects ${ }^{[5.6 .7]}$ and yields damping that is frequency independent and amplitude dependent. Some metals exhibit a high level of damping in the region of a transformation, for example, in the temperature range of a thermoelastic martensitic transformation. ${ }^{18.9]}$ Such thermoelastic damping is frequently amplitude independent and proportional to $|\dot{T}| / f$, where $|T|$ is the heating or cooling rate and $f$ is the frequency of vibration.

In this study, by using both resonant-bar and lowfrequency inverted torsion pendulum techniques, the damping capacity of TiNi alloys was investigated in the high-temperature cubic B2 parent phase (B2), the lowtemperature monoclinic $\mathrm{B} 19^{\prime}$ martensite phase $(\mathrm{M})$, and

H.C. LIN, Associate Professor, is with the Department of Materials Science, Feng-Chia University, Taichung, Taiwan 400, Republic of China. S.K. WU, Professor, is with the Institute of Materials Science and Engineering, National Taiwan University, Taipei, Taiwan 106, Republic of China. M.T. YEH is with the Materials R\&D Center, Chung-Shan Institute of Science and Technology, Lung-Tan, Taiwan 325, Republic of China.

Manuscript submitted February 15, 1993. the intermediate rhombohedral $\mathrm{R}$ phase $(\mathrm{R})$. The dominant damping mechanisms occurring in these phases and the characteristics associated with the thermoelastic transformations of TiNi SMAs are also discussed.

\section{EXPERIMENTAL PROCEDURES}

\section{A. Materials}

The conventional tungsten arc-melting technique was employed to prepare $\mathrm{Ti}_{49.8} \mathrm{Ni}_{50.2}$ and $\mathrm{Ti}_{49} \mathrm{Ni}_{51}$ alloys. Titanium (purity, $99.7 \mathrm{pct}$ ) and nickel (purity, $99.98 \mathrm{pct}$ ), totaling about $150 \mathrm{~g}$, were melted and remelted at least six times in argon atmosphere. Pure titanium buttons were also melted and used as a getter. The mass loss during melting was negligibly small. The as-melted buttons were homogenized at $1050{ }^{\circ} \mathrm{C}$ for 72 hours and quenched in water, then hot-rolled to plates with 2-mm thickness. Specimens for the resonant-bar damping test (size: $200 \times 15 \times 2 \mathrm{~mm}$ ) were carefully cut from these plates with a low-speed diamond saw. The rest of these plates were then hot-rolled to $1-\mathrm{mm}$ thickness and subsequently cut to be the specimens for the electrical resistivity measurement (size: $50 \times 1 \times 1 \mathrm{~mm}$ ) and internal friction test (size: $110 \times 4 \times 1 \mathrm{~mm}$ ). The cut specimens were sealed in evacuated quartz tubes, annealed at $800{ }^{\circ} \mathrm{C}$ for 2 hours, and quenched in water. Some $\mathrm{Ti}_{49} \mathrm{Ni}_{51}$ specimens were then aged in a $400{ }^{\circ} \mathrm{C}$ salt bath for 5 or 20 hours and quenched in water. The martensitic and premartensitic transformation temperatures were tested by using four-probe electrical resistivity and internal friction measurements.

\section{B. Damping Experiments}

There are a variety of experimental methods available to measure the damping properties of a material. Each technique has its own unique advantages, but they all yield equivalent measures of damping. ${ }^{[5]}$ In this study, two techniques, the flexural resonant-bar damping system and the internal friction, were used to measure the damping properties of TiNi alloys. The resonant-bar damping system is illustrated in Figure 1. The simple 


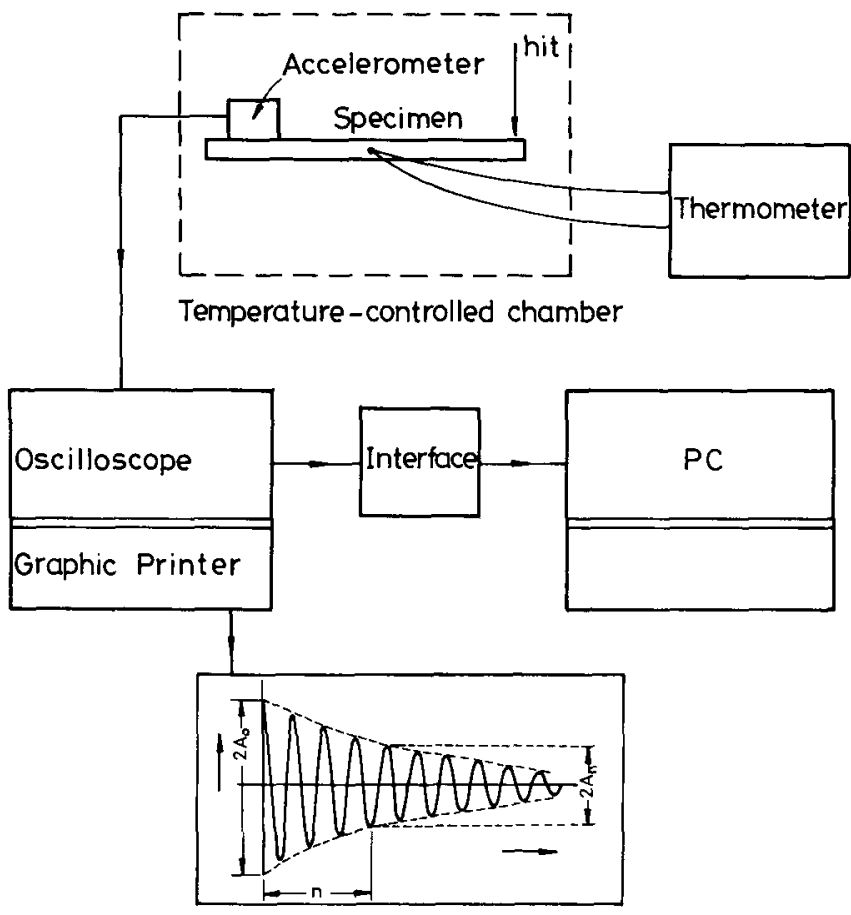

Fig. 1 - Schematic diagram of the resonant-bar damping system used in this study.

free-free cantilever beam can be excited into its fundamental mode of flexural vibration ${ }^{[10]}$ by an exciting steel ball. After the exciting steel ball hits the specimen, the amplitude of vibration gradually decreases with time as the vibrational energy is dissipated. These decayed amplitudes and frequency of vibration are transfered to an oscilloscope by an accelerometer attached on specimen's end. Measurement of successive strain amplitudes from the oscilloscope will then yield the logarithmic decrement, $\delta$ as follows:

$$
\delta=\ln \left(A_{n} / A_{n+1}\right)
$$

Where $A_{n}$ and $A_{n+1}$ are the amplitudes of successive cycles in free decay. The relationship between $\delta$, internal friction factor $Q^{-1}$, and damping ratio $\xi$ is given by ${ }^{[5]}$

$$
Q^{-1} \doteq 2 \xi \doteq \frac{\delta}{\pi}
$$

The specimen's temperature can be measured in situ by a thermometer and be controlled by a temperaturecontrolled chamber, as shown in Figure 1. Internal friction tests were carried out using a SINKU-RIKO $1500-\mathrm{M} / \mathrm{L}$ series inverted torsion pendulum in the temperature range from $-150{ }^{\circ} \mathrm{C}$ to $+100{ }^{\circ} \mathrm{C}$. The measuring frequency was about $1 \mathrm{~Hz}$, and the temperature changing rate $|\dot{T}|$ was set to be 1,2 , and $3{ }^{\circ} \mathrm{C} / \mathrm{min}$. Figure 2 shows typical experimental results of both the resonant-bar damping test and the internal friction measurement for $\mathrm{Ti}_{49.8} \mathrm{Ni}_{50.2}$ alloy. In Figure 2, one can find that the variation of the damping property measured by these two techniques behaves with a similar tendency. Namely, the higher the internal friction, the faster the amplitude decay (or the higher the $\delta$ value).

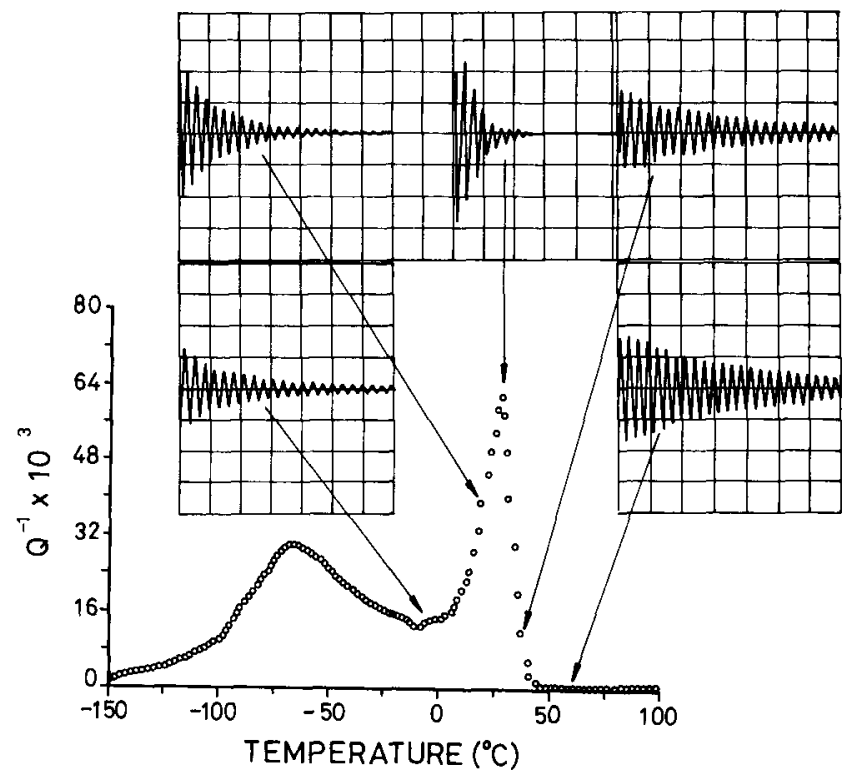

Fig. 2-Typical experimental plots of both the resonant-bar damping test and internal friction measurement for the $\mathrm{Ti}_{49.8} \mathrm{Ni}_{50.2}$ alloy.

\section{EXPERIMENTAL RESULTS}

\section{A. Experimental Results of the Resonant-Bar Damping Test}

In order to understand the damping property of TiNi SMAs, including the B2 and R phases and B19' martensite, the resonant-bar damping tests were carried out at various temperatures, where TiNi alloys exhibit different phases during cooling. All the experimental results, involving testing temperatures, existing phases, the damping ratio $\xi$, and resonant frequency $f$ are summarized in Tables I and II for $\mathrm{Ti}_{49.8} \mathrm{Ni}_{50.2}$ alloy and $400{ }^{\circ} \mathrm{C} \times 20 \mathrm{~h}$ aged $\mathrm{Ti}_{49} \mathrm{Ni}_{51}$ alloy, respectively. In order to further show the relationship between the damping property and existing phases, damping ratio $\xi$ and electrical resistivity are plotted $v s$ temperature in Figures 3 and 4 for the solution-treated $\mathrm{Ti}_{49.8} \mathrm{Ni}_{50.2}$ and $400{ }^{\circ} \mathrm{C} \times 20 \mathrm{~h}$ aged $\mathrm{Ti}_{49} \mathrm{Ni}_{51}$ alloy, respectively. In Figure 3, the damping ratio $\xi$ of martensite is larger than that of the B2 phase and there is a sharp peak of $\xi$ in the temperature range of the $\mathrm{B} 2 \rightarrow \mathrm{M}$ transformation. In Figure 4, the damping ratio $\xi$ of martensite has nearly the same magnitude as that of the $\mathrm{R}$ phase but is larger than that of the B2 phase. The peaks of the damping ratio $\xi$ appear in the temperature ranges of the $\mathrm{B} 2 \rightarrow \mathrm{R}$ and $\mathrm{R} \rightarrow \mathrm{M}$ transformations. The characteristics of the damping shown in Figures 3 and 4 will be discussed in Section IV.

\section{B. Experimental Results of Internal Friction Measurement}

Figures 5(a) and (b) show plots of the internal friction $Q^{-1} v s$ temperature for the solution-treated $\mathrm{Ti}_{49.8} \mathrm{Ni}_{50.2}$ and $400{ }^{\circ} \mathrm{C} \times 5 \mathrm{~h}$ aged $\mathrm{Ti}_{49} \mathrm{Ni}_{51}$ alloys, respectively. In Figure 5(a), it appears that transformation peaks, $P_{\mathrm{C} 1}$ and $P_{\mathrm{Hl}}$, and relaxation peaks, $P_{\mathrm{CR}}$ and $P_{\mathrm{HR}}$, on the cooling and heating cycles. Peaks $P_{\mathrm{C} 1}$ and $P_{\mathrm{H} 1}$ are associated with 
Table I. The Existing Phases, Damping Ratio $\xi$, and Resonant

Frequency $f$ in Different Damping Testing Temperatures for the $\mathrm{Ti}_{49.8} \mathbf{N i}_{50.2}$ Alloy

\begin{tabular}{|c|c|c|c|c|c|c|c|c|c|}
\hline Temperature $\left({ }^{\circ} \mathrm{C}\right)$ & 60 & 45 & 34 & 30 & 25 & 20 & 10 & 0 & -9 \\
\hline Phases & $\mathrm{B} 2$ & $\mathrm{~B} 2$ & $\mathrm{~B} 2+\mathrm{M}$ & $\mathbf{B} 2+\mathbf{M}$ & $\mathrm{B} 2+\mathrm{M}$ & $\mathbf{B} 2+\mathbf{M}$ & $\mathbf{M}$ & $\mathbf{M}$ & $\mathbf{M}$ \\
\hline Damping ratio $\xi$ & 0.009 & 0.010 & 0.013 & 0.030 & 0.051 & 0.036 & 0.021 & 0.020 & 0.021 \\
\hline$f(\mathbf{H z})$ & 167 & 166 & 158 & 153 & 150 & 151 & 155 & 155 & 156 \\
\hline
\end{tabular}

Table II. The Existing Phases, Damping Ratio $\xi$, and Resonant Frequency $f$ in Different Damping Testing Temperatures for the $400{ }^{\circ} \mathrm{C} \times 20 \mathrm{~h}$ Aged $\mathrm{Ti}_{49} \mathrm{Ni}_{51}$ Alloy

\begin{tabular}{|c|c|c|c|c|c|c|c|c|c|c|c|c|}
\hline Temperature $\left({ }^{\circ} \mathrm{C}\right)$ & 75 & 60 & 45 & 39 & 37 & 30 & 15 & -5 & -15 & -21 & -30 & -45 \\
\hline Phases & B2 & B2 & $\mathbf{B} 2+\mathbf{R}$ & $\mathrm{B} 2+\mathrm{R}$ & $\mathbf{B} 2+\mathbf{R}$ & $\mathrm{B} 2+\mathrm{R}$ & $\mathrm{R}$ & $\mathrm{R}+\mathrm{M}$ & $\mathbf{R}+\mathbf{M}$ & $\mathbf{R}+\mathbf{M}$ & M & $\mathbf{M}$ \\
\hline Damping ratio $\xi$ & 0.009 & 0.010 & 0.014 & 0.025 & 0.045 & 0.034 & 0.028 & 0.037 & 0.053 & 0.040 & 0.026 & 0.026 \\
\hline$f(\mathbf{H z})$ & 155 & 155 & 138 & 130 & 119 & 125 & 136 & 137 & 135 & 141 & 146 & 147 \\
\hline
\end{tabular}

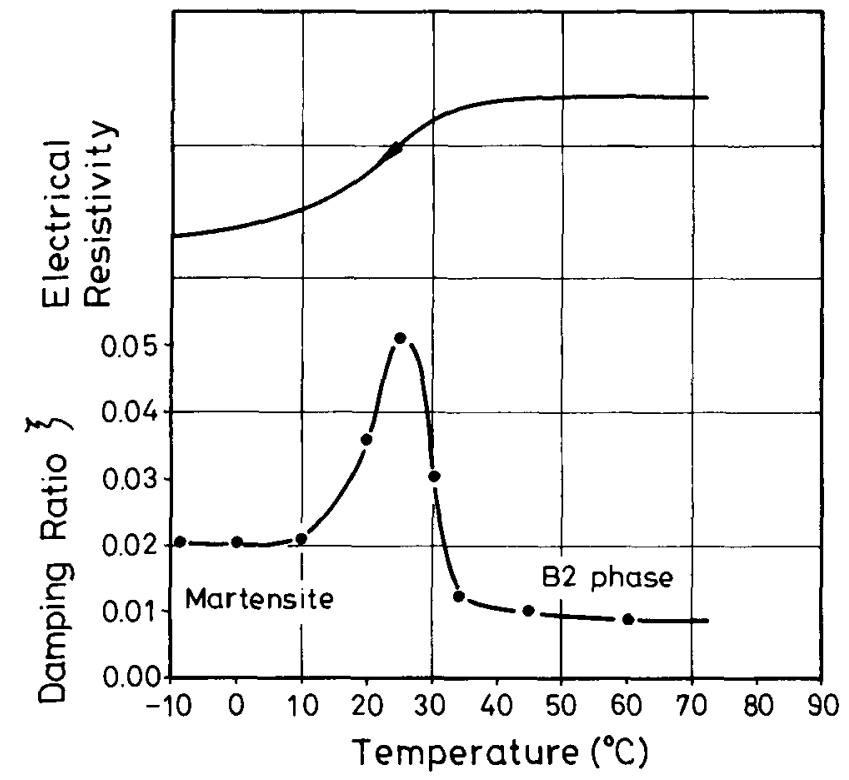

Fig. 3-Damping ratio $\xi$ and electrical resistivity $v s$ temperature curves for the $\mathrm{Ti}_{49.8} \mathrm{Ni}_{50.2}$ alloy.

the martensitic transformation, ${ }^{[1.31}$ while peaks $P_{\mathrm{CR}}$ and $P_{\mathrm{HR}}$ are related to the relaxation of dislocation damping. ${ }^{[2]}$ In Figure $5(\mathrm{~b})$, the $P_{\mathrm{Cl}}$ and $P_{\mathrm{H} 1}$ peaks are also associated with the martensitic transformation while $P_{\mathrm{C} 2}$ and $P_{\mathrm{H} 2}$ peaks are associated with the premartensitic $\mathrm{R}$ phase transformation. Comparing Figures 5(a) and (b) to Figures 3 and 4 , one can find that the $Q^{-1}$ value from the internal friction measurement as a function of temperature behaves similarly to the damping ratio $\xi$ obtained from resonant-bar damping tests. Both the B19' martensite and $\mathrm{R}$ phase exhibit a same-order damping capacity which is larger than the B2 phase, and the damping capacity peaks appear in the temperature ranges of the martensitic and premartensitic transformation regions in TiNi SMAs.

The height of the transformational peaks, $P_{\mathrm{C} 1}, P_{\mathrm{H} 1}$, $P_{\mathrm{C} 2}$, and $P_{\mathrm{H} 2}$, of Figure 5 can be affected by the heating or cooling rate $\dot{T}$, as shown in Figure 6. Figures 6(a) and (b) present these peak heights as a function of $\dot{T}$ without subtraction of the background for the $\mathrm{Ti}_{49.8} \mathrm{Ni}_{50.2}$ and $400{ }^{\circ} \mathrm{C} \times 5 \mathrm{~h}$ aged $\mathrm{Ti}_{49} \mathrm{Ni}_{51}$ alloys, respectively. A linear variation of these heights $v s T$ is observed. When extrapolated to $\dot{T}=0$, these heights do not approach zero

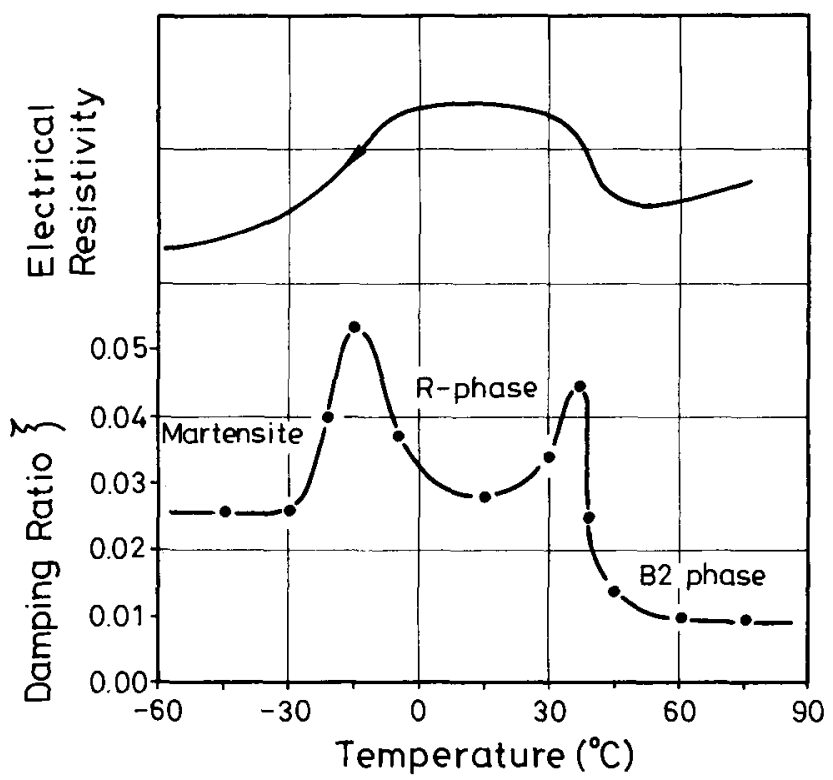

Fig. 4-Damping ratio $\xi$ and electrical resistivity $v s$ temperature curves for the $400^{\circ} \mathrm{C} \times 20 \mathrm{~h}$ aged $\mathrm{Ti}_{49} \mathrm{Ni}_{51}$ alloy.

but some constant value higher than the background. This characteristic will be discussed in Section IV.

\section{DISCUSSION}

A. The Damping Capacity and Damping Mechanism of B2, B19', and $R$ Phases in TiNi Alloys

As mentioned in Section I, most damping mechanisms involve the stress-induced movement of defects. ${ }^{[5]}$ Point defects give rise to damping in the range of low to intermediate levels, line defects give rise to damping levels in the intermediate to high range, and planar defects give rise to damping levels in the high range. It is well known that there are abundant twin boundaries in the B19' martensite and $\mathrm{R}$ phase of TiNi alloys. ${ }^{[11,12]}$ These twin boundaries can be easily moved by the external stress to accommodate the strain. This phenomenon is the wellknown "accommodation/reorientation" process occurring in the martensite and $\mathrm{R}$ phase of the deformed TiNi alloys. We postulate that this accommodation/reorientation phenomenon is closely related to the high damping capacity of TiNi alloys and propose the following damping 


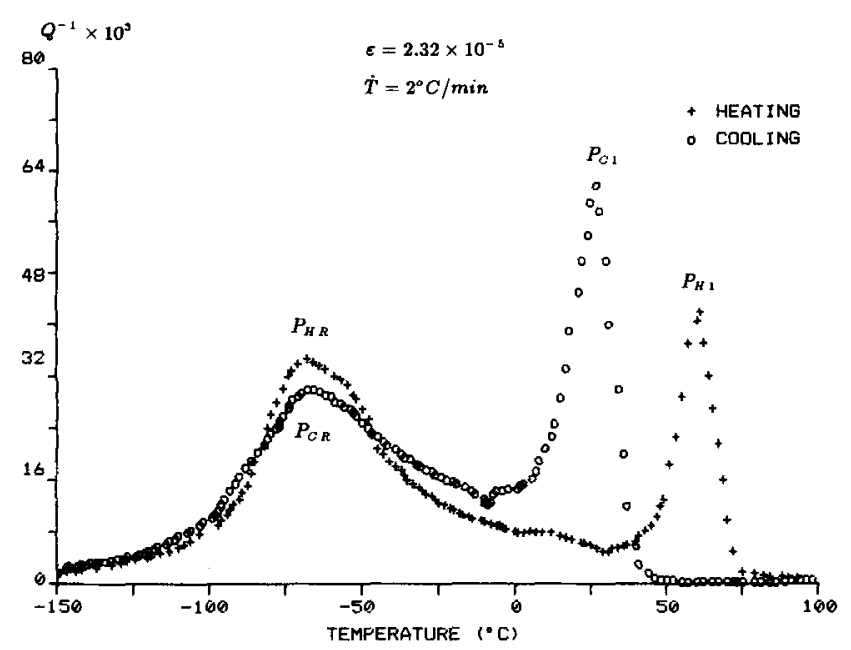

(a)

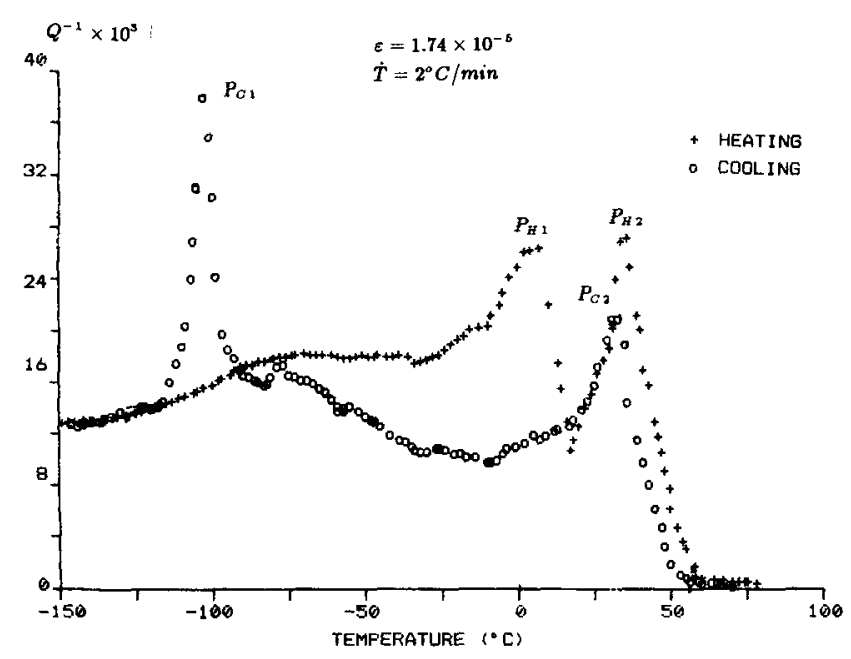

(b)

Fig. 5-Internal friction $v s$ temperature curves for $(a) \mathrm{Ti}_{49.8} \mathrm{Ni}_{50.2}$ alloy and $(b) 400{ }^{\circ} \mathrm{C} \times 5 \mathrm{~h}$ aged $\mathrm{Ti}_{49} \mathrm{Ni}_{51}$ alloy.

mechanism to account for this relationship. The stressstrain diagram for the accommodation/reorientation process during the damping test is schematically drawn in Figure 7. Also, Muller et al. had recently studied the stress-strain curve of the pseudoelastic hysteresis on the $\mathrm{CuZnAl}$ single crystal. ${ }^{[13]}$ However, in our proposed diagram of Figure 7, it is shown that after an elastic response to the stress, an accommodated strain $\varepsilon_{a}$ in some microdomains can be produced at a critical value of the stress, $\sigma_{a}$. This strain is due to the stress-induced movement of twin boundaries between the variants of martensite or $\mathbf{R}$ phase. The accommodated strain is retained during the unloading but can be reoriented to the opposite direction due to the movement of twin boundaries induced by the following opposite-direction stress, $-\sigma_{a}$. This opens up a relatively large static hysteresis loop, $\Delta W$, for the cyclic movement of twin boundaries. Therefore, the martensite and $\mathrm{R}$ phase of $\mathrm{TiNi}$ alloys have a high-damping capacity, comparable to or even higher than cast irons. ${ }^{[14,15]}$ The high-damping properties due to the movement of twin boundary have also been observed in (a)

(b)
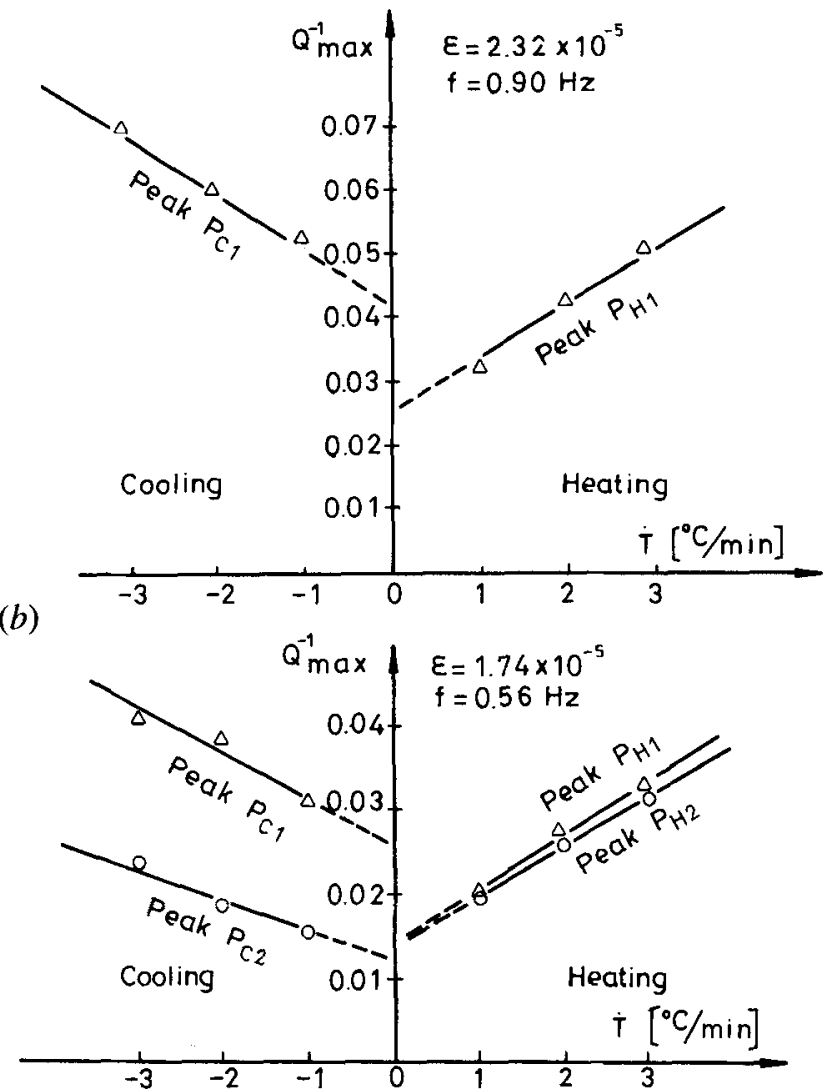

Fig. 6-The internal friction peak heights $\left(Q_{\max }^{-1}\right)$ vs temperature changing rate $(T)$ for $(a) \mathrm{Ti}_{49.8} \mathrm{Ni}_{50.2}$ alloy and $(b) 400{ }^{\circ} \mathrm{C} \times 5 \mathrm{~h}$ aged $\mathrm{Ti}_{49} \mathrm{Ni}_{s_{1}}$ alloy.

the Mn-Cu-based alloys ${ }^{[16]}$ and some Cu-based shape memory alloys. ${ }^{[17,18]}$

No twin boundaries exist in the parent $\mathrm{B} 2$ phase of TiNi alloys, and the dislocation density in the matrix is quite low. ${ }^{.19]}$ Hence, the damping capacity is suggested simply to come from the dynamic hysteresis of lattice defects, such as vacancy or interstitial. The stress-induced ordering process of these defects leads to an anelastic strain, and the damping mechanism is referred to as a linear reversible anelastic relaxation and opens up the dynamic hysteresis loop. Because the dynamic hysteresis loop generally dissipates a smaller quantity of energy, the damping capacity in the B2 phase of TiNi alloys is smaller, as shown in Figures 3 through 5.

\section{B. The Damping Property Associated with Thermoelastic Phase Transformations in TiNi Alloys}

As discussed in Section IV-A, the martensite and $R$ phase of TiNi alloys have a high damping capacity due to the movement of twin boundaries, but the parent B2 phase shows a low-damping capacity which is suggested simply to come from the dynamic ordering process of lattice defects. In Figures 3 through 5, there are peaks of damping capacity in the transformation regions of B2 $\leftrightarrow \mathrm{M}, \mathrm{B} 2 \leftrightarrow \mathrm{R}$, and $\mathrm{R} \leftrightarrow \mathrm{M}$. The maximum value of the damping capacity occurring in the temperature ranges of transformation is two times or even higher that 


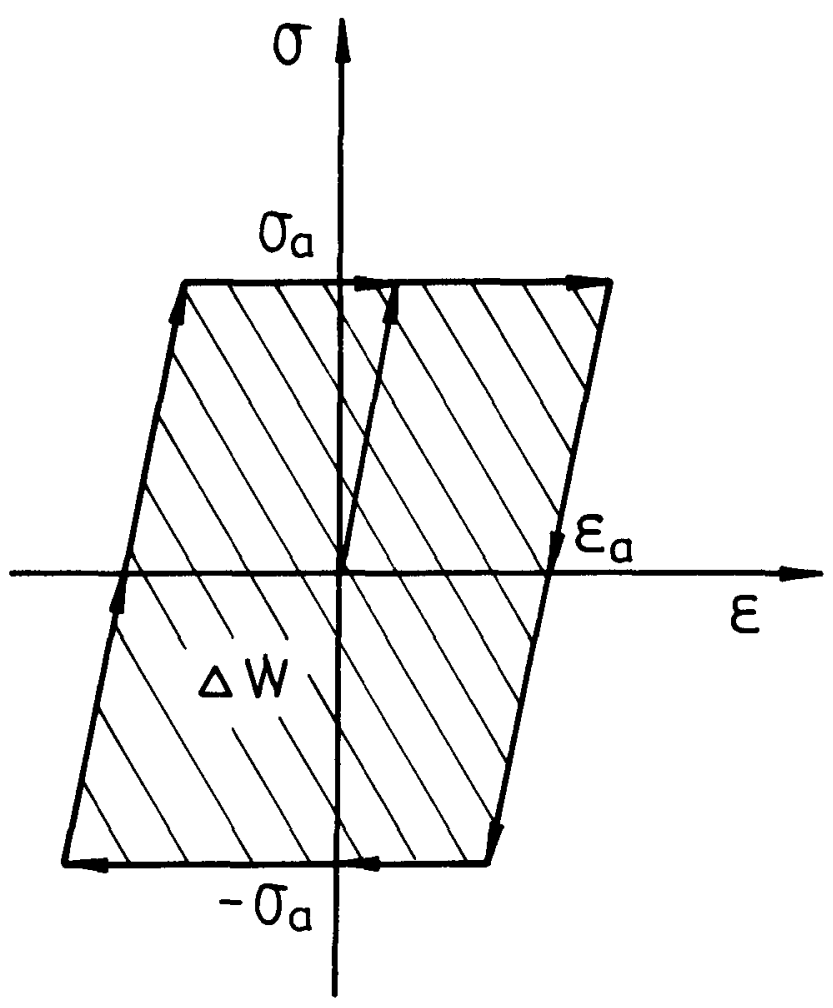

Fig. 7-Schematic stress-strain diagram for the martensite/R phase accommodation/reorientation process. $\Delta W$ indicates the energy loss for the cycling movement of twin boundaries.

occurring in martensite or the $\mathrm{R}$ phase. This feature of high-damping capacity associated with the phase transformations of TiNi alloys needs to be further understood.

Postnikov et al. ${ }^{[20]}$ had shown that all the first-order phase transformations should be accompanied with an internal friction peak, which is explained by the difference in volume between the two phases. Delorme et al. ${ }^{[21]}$ extended the Postnikov's model by considering the plastic strain during transformation and deduced the internal friction factor $Q^{-1}$ as a function of temperature rate, $d T / d t$ :

$$
Q^{-1}=\frac{1}{w} \frac{d \psi\left(V_{m}\right)}{d V_{m}} \cdot \frac{d V_{m}}{d T} \cdot \frac{d T}{d t}
$$

where $V_{m}$ is the volume fraction of martensite, $w$ is the angular frequency of applied stress, and $\psi\left(V_{m}\right)$ is a monotonic function associated with the transformation volume change and/or shape strain. Equation [3] indicates that the internal friction factor $Q^{-1}$ is proportional to the heating and cooling rate, $T$. Dejonghe et al.,$^{[22]}$ in order to take account of the special character of the martensite which can be induced or reoriented by an external stress $\sigma$, introduced the stress dependence to $d V_{m} / d t$ as the following:

$$
\frac{d V_{m}}{d t}=\frac{\partial V_{m}}{\partial T} \cdot \frac{\partial T}{\partial t}+\frac{\partial V_{m}}{\partial \sigma} \cdot \frac{\partial \sigma}{\partial t}
$$

In Eq. [4], the first term is identical to the Delorme's model and the second term is the stress-dependent one.
In Figures 6(a) and (b), an approximately linear variation of peak heights $Q_{\max }^{-1}$ of $P_{\mathrm{H} 1}, P_{\mathrm{C} 1}, P_{\mathrm{H} 2}$, and $P_{\mathrm{C} 2} v s$ $\dot{T}\left(\dot{T}=1,2,3{ }^{\circ} \mathrm{C} / \mathrm{min}\right)$ is observed. This result indicates that both martensitic and R-phase transformations agree with the Delorme's model at $\dot{T}=1{ }^{\circ} \mathrm{C} / \mathrm{min}$ to $3{ }^{\circ} \mathrm{C} / \mathrm{min}$. Besides, in Figures 6(a) and (b), as $T$ is extrapolated to zero, the peak heights are higher than the background. At $\dot{T}=0$, no martensite or $\mathrm{R}$ phase is formed by a thermal driving force, but either can be formed by the applied external stress. In TiNi alloys, the deformation behavior shows that the stress-induced transformation occurs before the reorientation of variants of martensite or $\mathbf{R}$ phase in the temperature range of forward transformations on cooling. ${ }^{[19]}$ Hence, the damping capacity appearing at $\dot{T}=0$ on cooling, as shown in Figure 6, is ascribed to the stress-induced transformation. Tadaki et al. ${ }^{[23]}$ have reported that the volume change and shape strain associated with the martensitic transformation are much larger than those associated with the R-phase transformation. Based on this report, $d \psi\left(V_{m}\right) / d V_{m}$ for martensitic transformation is larger than that for R-phase transformation. Therefore, the internal friction of the $\mathrm{R} \rightarrow \mathrm{M}$ transformation should be much larger than that of the B2 $\rightarrow \mathrm{R}$ transformation. Therefore, the $P_{\mathrm{Cl}}$ peak $(\mathrm{R} \rightarrow \mathrm{M})$ at $\dot{T}=0$ is much higher than the $P_{\mathrm{C} 2}$ peak (B2 $\rightarrow \mathrm{R})$ at the same strain amplitude. However, in the heating process, the existing martensite or R-phase variants should be reoriented to accommodate the applied strain. As discussed in Section III-A, the damping capacities due to the stress-induced movement of the twin boundary in the accommodation/reorientation process for martensite and $\mathrm{R}$ phase have nearly the same magnitude. Hence, the peak heights $Q_{\max }^{-1}$ of $P_{\mathrm{H} 1}$ and $P_{\mathrm{H} 2}$ at $\dot{T}=0$ have nearly the same values, as shown in Figure 6(b).

Recently, Zhu et al. ${ }^{[24]}$ reported that the relationship between $Q^{-1}$ and $\dot{T} / f$ for TiNi alloy is nonlinear, especially for $\dot{T}<1{ }^{\circ} \mathrm{C} / \mathrm{min}$, contrary to the linear relation of Delorme's theory. This feature can be reasonably explained as follows. As discussed earlier, the damping can arise from both thermal (cooling or heating) and mechanical (external stress) driving forces. If $\dot{T}$ is higher, the damping capacity is dominated by the thermal driving force, hence, Delorme's model is reasonable and the relation between $Q^{-1}$ and $\dot{T} / f$ is approximately linear, as shown in Figure 6 for $\dot{T}=1{ }^{\circ} \mathrm{C} / \mathrm{min}$ to $3{ }^{\circ} \mathrm{C} / \mathrm{min}$. However, when $\dot{T}$ is lower $\left(e . g .,<1{ }^{\circ} \mathrm{C} / \mathrm{min}\right)$, the damping capacity is dominated by the external stress and cannot be predicted by Delorme's theory.

\section{The Elastic Modulus E in TiNi Alloys}

In addition to the variation of the damping capacity with temperature in $\mathrm{TiNi}$ alloys, it can also be found that in Tables 1 and 2 , the resonant frequencies $f$ of martensite and R phase are lower than that of the B2 phase. There are frequency minima in the temperature ranges for both martensitic and R-phase transformations. This phenomenon was also found in internal friction measurements. ${ }^{12,3]}$ The resonant frequency is proportional to the square root of the elastic modulus $E, f \propto \sqrt{E}$. Hence, the experimental results indicate that the B2 phase has a higher elastic modulus than the martensitic and $R$ phases, and there are modulus minima in the temperature ranges 
of transformations. This result is consistent with some reports in which the modulus is measured from stressstrain curves. ${ }^{[25]}$ Comparing the resonant frequency in Table I with that in Table II, one can find that the resonant frequency of $\mathrm{Ti}_{49.8} \mathrm{Ni}_{50.2}$ alloy is higher than that of $400{ }^{\circ} \mathrm{C} \times 20 \mathrm{~h}$ aged $\mathrm{Ti}_{49} \mathrm{Ni}_{51}$ alloy. This indicates that the elastic modulus of the former alloy is higher than that of the latter alloy. The precipitates and/or matrix composition difference may be related to this feature.

\section{CONCLUSIONS}

The damping characteristics of TiNi SMAs have been systematically studied by using resonant-bar and lowfrequency inverted torsion pendulum techniques. Both B19' martensite (M) and $R$ phase (R) have a high-damping capacities due to the stress-induced movement of twin boundaries. On the other hand, the parent B2 phase has a smaller damping capacity which is suggested simply to come from the dynamic ordering process of lattice defects. In the transformation regions of B2 $\leftrightarrow \mathrm{M}$, B2 $\leftrightarrow \mathrm{R}$, and $\mathrm{R} \leftrightarrow \mathrm{M}$, there are damping capacity maxima which are two or more times higher than the damping capacity of martensite or $R$ phase. Two contributions are proposed to account for the occurrence of the maxima of damping capacity. One arises from the plastic strain and twin-interface movement during the thermal-induced transformation, which obeys a linear variation of peak heights $Q_{\max }^{-1} v s$ heating or cooling rate $\dot{T}$ at $\dot{T} \geq$ $1{ }^{\circ} \mathrm{C} / \mathrm{min}$. The other originates from the stress-induced transformation caused by the applied external stress which dominates at $\dot{T}<1{ }^{\circ} \mathrm{C} / \mathrm{min}$. The experimental results indicate that the elastic moduli $E$ of martensite and the $R$ phase are lower than that of the $B 2$ phase in TiNi SMAs, and there are modulus minima existing in the transformation regions.

\section{ACKNOWLEDGMENTS}

The authors are pleased to acknowledge the financial support of this research by the National Science Council (NSC), Republic of China, under Grant No NSC 82-0405E002-080. The authors thank Mr. T.S. Chou, China Steel Corporation, for his excellent assistance in the internal friction measurement. Also, we would like to thank Dr.
Y.C. Lo, Institute of Materials Science and Engineering, National Taiwan University, Taipei, Taiwan, for helpful discussions during the research process.

\section{REFERENCES}

1. O. Mercier, K.N. Melton, and Y.De. Preville: Acta Metall., 1979, vol. 27, pp. 1467-75.

2. K. Iwasaki and R. Hasiguti: Trans. JIM, 1987, vol. 28, pp. 363-67.

3. S.K. Wu, H.C. Lin, and T.S. Chou: Acta Metall. Mater., 1990, vol. 38 , pp. $95-102$.

4. C.M. Jackson, H.J. Wagner, and R.J. Wasilewski: NASA-SP 5110,1972 , pp. 35-41.

5. I.G. Ritchie and Z.-L. Pan: Metall. Trans. A, 1991, vol. 22A, pp. 607-16.

6. R. de Batist: Internal Friction of Structural Defects in Crystalline Solids, North-Holland Publishing Co., Amsterdam, 1972

7. D.W. James: Mater. Sci. Eng., 1969, vol. 4, pp. 1-8.

8. R. de Batist: J. Phys., 1983, pp. C9-39.

9. J. Van Humbeeck: Proc. ASM Materials Week and TMS/AIME Fall Meeting, Role of Interfaces on Materials Damping, 1985 , pp. 5-24.

10. A.S. Nowick and B.S. Berry: Anelastic Relaxation in Crystalline Solid, Academic Press, New York, NY, 1972.

11. T. Saburi and S. Nenno: Proc. Int. Conf. on Solid to Solid Phase Trans., ASM, Metals Park, OH, 1982, pp. 1455-79.

12. S. Miyazaki and C.M. Wayman: Acta Metall., 1988, vol. 36, pp. 181-92.

13. I. Muller and H. Xu: Acta Metall. Mater., 1991, vol. 39, pp. 263-71.

14. M.T. Yeh, H.C. Lin, and S.K. Wu: National Taiwan University, Taipei, Taiwan, unpublished research, 1993.

15. W.J. Buehler and R.C. Wiley: Report NOLTR 61-75, U.S. Naval Ordinance Laboratory, Silver Spring, MD, Aug. 3, 1961.

16. A.F. Schwaneke and J.W. Jensen: J. Appl. Phys., 1962, vol. 33, pp. 1350-51.

17. K. Sugimoto, T. Mori, K. Otsuka, and K. Shimizu: Scripta Metall., 1974, vol. 8, pp. 1341-46.

18. M. Morin, G. Guenin, S. Etienne, and P.F. Gobin: Trans. JIM, 1981, vol. 22 , pp. 1-5.

19. S. Miyazaki and K. Otsuka: Metall. Trans. A, 1986, vol. 17A, pp. 53-63.

20. V.S. Postnikov, S.A. Gidnev, B.M. Darinskii, and I.M. Sharashakov: Nuovo Cim. B, 1976, vol. 33, pp. 324 .

21. J.F. Delorme, R. Schmid, M. Robin, and P. Gobin: J. Phys., 1971, vol. 32, pp. C2-101-09.

22. W. Dejonghe, R. De Batist, and L. Delaey: Scripta Metall., 1976, vol. 10 , pp. 1125-28

23. T. Tadaki, Y. Nakata, and K. Shimizu: Trans. JIM, 1987, vol. 28 , pp. $883-90$.

24. J.S. Zhu, R. Schaller, and W. Benoit: Phys. Status Solidi A, 1988, vol. 108, pp. 613-18.

25. K.N. Melton and O. Mercier: Acta Metall., 1980, vol. 29, pp. 393-98. 